\title{
Starting Mindful Connections in Occupational Therapy Education
}

Aricka Schweitzer EdD, MSOT, OTRL, C/NDT

Assistant Professor of Occupational Therapy, Saginaw Valley State University, United States.

\author{
Article Details \\ Article Type: Short Communication \\ Received date: $07^{\text {th }}$ March, 2020 \\ Accepted date: $02^{\text {nd }}$ April, 2020 \\ Published date: $04^{\text {th }}$ April, 2020
}

"Corresponding Author: Aricka Schweitzer EdD, MSOT, OTRL, C/NDT, Assistant Professor of Occupational Therapy, Saginaw Valley State University, United States. E-mail: aabartle@svsu.edu

Citation: Schweitzer, A. (2020). Starting Mindful Connections in Occupational Therapy Education. J Rehab Pract Res 1(1):103. https://doi.org/10.33790/jrpr1100103

Copyright: (C2020, This is an open-access article distributed under the terms of the Creative Commons Attribution License 4.0, which permits unrestricted use, distribution, and reproduction in any medium, provided the original author and source are credited.

\begin{abstract}
s
The mind-body connection is one that is programmed and works best when there is a balance of interaction and reactions. The purpose of this short communication paper is to discuss the meaningful connection that occurs when educators prepare student's minds for learning. Students are entering higher education with many life stressors and helping students to quiet their minds in preparation to learn has the potential to improve student success. The pilot included the integration of two mindfulness activities and exercises into a 400 level higher education psychosocial course and students reflected on the effects of the activities on their ability to attend and readiness to learn. $87.5 \%$ of students reported that the use of the activities helped them concentrate and reduced anxiousness. The continued infusion of mindful and mind-body connected activities seems of value based on the upcoming generations being served in higher education, but also for student success in classes within the higher education context.
\end{abstract}

Keywords: Higher Education, Mindfulness, Mind-body Connection, and Student Stress

\section{Starting Mindful Connections in Occupational Therapy Education}

In academia, many ideas can be introduced and addressed as innovative teaching. The use of mindfulness as it relates to the connection between the mind and body are not new as stated by [1], but the application of how they are used in a classroom might be a "new" and innovative way of setting up the mind for success. When preparing for a long day of learning, particularly in the higher education setting, the mind must be ready to take in and process information to facilitate the connections in the brain, which then retains the information. The faculty member explored how mindfulness exercises can be used to help facilitate greater student readiness to learn and improve alertness in a course. In this short paper, an innovative teaching strategy and the informal outcomes will be discussed on how the instructor-facilitated different preparedness activities to ready student's minds for learning and prepared the mind to rest through the use of mindfulness exercises embedded in a course. The literature will also scope the use of mind-body connections and historical and generational use of mindfulness activities.

\section{Introduction}

The students entering the higher education setting are a diverse group, with many experiences shaping their thoughts of what higher education may be like. Not only are the students from wide backgrounds and experiences, but many students are entering higher education with high levels of anxiety and helping prepare students mentally for a class is something that may need to be considered in future preparatory courses. Literature supports that in education, encouraging healthy eating patterns, getting enough sleep, exercising, and managing stress are all ways to help the body and mind prepare for class [2]. However, with balancing student schedules and the academic work that comes with them, extracurriculars, work, and leisure, students have developed poor coping habits and are struggling with unmanageable stress in the classroom. Not only does the stress affect the student in physical ways, but the stress that is placed on students to achieve high marks and accelerate in their courses is high as well [3]. Lastly, Pascoe et al. [20] supported in their findings that increasing student stress management is a key target for change. The use of mindfulness in the classroom as an outlet, along with preparation strategies for successful learning may help combat some unnecessary academic stress.

According to Cavanagh [4], faculty members are not well prepared to respond to students experiencing stress or anxiety, as they need to be respectful of the learning goals of the higher education context. This problem and preparedness are not just experienced for the typical presentation anxiety that is felt within classes but, class functions and environments in general. Students are coming to higher education environments from broken homes, issues with parenting, and stressful new or expanding independence roles. With a lot on student's shoulders, as educators of this future generation, the need to evaluate how faculty are preparing for the upcoming generation not only to learn, but also to help them help themselves when it comes to their educational goals. I suspect that not all faculty will have this concern at the forefront of their agenda; however, student satisfaction and faculty influence on student engagement experiences do improve student satisfaction measures for the university [5]. Additionally, Cavanagh [4] discussed that the learning environment must be supportive for students experiencing anxiety, and several pedagogical approaches can enhance the environment by nurturing the intellect of the students but also their emotional lives.

Mindfulness training (MFT) can be used as a treatment type to assist those who may have diagnoses of anxiety; however, it can also be used for the layperson to relax the mind. When discussing the term and use of mindfulness, it can be defined best by [1] as "the intentional focus on one's attention to the present moment in a non-judgmental way" (p. 2). This form of focus will be elaborated upon further when discussing the application of mindfulness exercises in the course. According to Björkstrand et al. [6], MFT exerts some beneficial effects on psychological functions such as increased attention and emotional regulation, not only those positive aids, but mindfulness can also have a positive impact on present learning and memory. By using MFT and mindfulness approaches in the classroom, it has the potential to help to reduce anxiousness and maladaptive behaviors; 
therefore, allowing the student to take in the new learning concepts to be covered that day. By positioning the mind and readying the student to learn, the student can become more engaged in their educational role.

\section{Method}

The application of the mindful exercises began with the idea to help quiet the student's mind and prepare them to learn challenging concepts in a course that discusses psychosocial disorders. The students engaged in two separate mindfulness sessions, one at the beginning of the course and one at the conclusion of the course. According to Armstrong [1] best practice for mindfulness exercises range from 10-20 minutes, and the mindful activities or exercises were guided from a children's mindfulness text and were modified and expanded to meet the needs of the population served. For implementation, each mindful session lasted 5-10 minutes to follow best practice guidelines. Armstrong [1] also suggested that exercises be modified or adapted to fit and serve the needs of the population. Since the population that was engaging in the activities was of higher education students; consequently, the language in the guided exercises was adapted from children's terminology to adult when referring to verbal directions.

The connection between the mind and the body is very strong. Jacobs [7] supported the mind-body connection impacting the relaxation response in our body through changing mental activity, which plays a pivotal role in the mechanisms of the highest thought processes. Furthermore, the potential value of unstructured, interactive, or spontaneous motions has a favorable impact on creative performance [8]. Therefore, the mindfulness exercises that were used, included a blend and connection to both physical activity and mental activities. Some of the mindful exercises had students following step by step verbal directions and demonstrating movements or stretching, while other exercises encouraged awareness of breathing. Other creative blending activities focused on awareness of posture, or awareness of their surroundings. The students were led by the faculty member through the exercises or activities each class period, which positioned their mind to "wake up" and become ready to learn.

At the end of the course, students were informally surveyed and asked if the mindfulness exercises helped center their attention and promote readiness for the class that date. Students when signing into the course were handed sticky notes to submit at the end of the class period. After the initial mindful exercise and culminating class exercise students were encouraged to make any notes about how they felt on the sticky note. As an exit ticket from class, to stay anonymous students were asked about the mindful exercise and placed their sticky note on the board corresponding to how they felt in response to the activity.

\section{Results}

Before the engagement of these mindful exercises, students would arrive and struggle with preparing for the new learning that was to occur. By integrating the mind and the body, students positioned themselves around the room, engaged in relaxing their mind, and it had been found that a majority commented in a shared class discussion that it 'put their mind at ease', allowing them to engage in the class differently. Students also commented as a part of an in-class discussion that they experienced a "quieter mind" and that they were able to focus on the material in comparison to when their thoughts wandered in a normal class.

The mindful exercises were only completed on low-stakes class days, which were class periods planned in the semester that did not have presentations or examinations. The mindfulness activities were completed twice a class and at the end of the class, students submitted their comment on how they felt by noting their response on their anonymous sticky note. Anecdotal evidence from the informal student response revealed that initially, $90 \%$ of the students when asked if they felt "ready to learn" agreed that the mindful activity helped them relax, feel less stressed, and ready to learn. Another class period when asked specifically to respond on the board about the student's ability to "focus their concentration skills and stillness of their mind", $87.5 \%$ reported on their sticky note, that they were able to concentrate and felt like they had reduced anxiousness. The other $12.5 \%$ that date stated they were "unsure" whether or not it helped. In the future defining exactly what they were to concentrate on may help in more successful reporting.

The class is a course focused on psychosocial conditions that are seen in everyday healthcare, so the discussions and content are unique as they are learning about causes and symptoms related to mental health, schizophrenia, autism spectrum disorder, anxiety, and mood disorder to name some. Not only is the content delivered uniquely, but the course is a three-hour course beginning at 8:30 am; therefore, extra efforts for engagement and sustained attention were necessary.

\section{Conclusion}

In conclusion, the use of mindfulness exercises in the course seemed to be making a difference in the attention and stress management of the students. The potential for student success can come in many different ways; however, as an educator seeing greater successes in formal assessment as well as informal student sticky note commentary, makes it more reassuring to continue to implement the mindful exercises. Although not all students seem to enjoy the activities, it is not always possible to make everyone happy from an instructor's point of view. The continued infusion of mindful and mind-body connected activities seems of value, based on the upcoming generations being served in higher education, but also for student success in classes within the higher education context. It would be interesting to explore the use of mindful activities in introductory courses to see if students can integrate these patterns for future course planning and overall greater stress management.

Conflict of interest: The authors have declared no conflict of interest.

\section{References}

1. Armstrong, T. (2019). Mindfulness in the classroom: Strategies for promoting concentration, compassion, and calm. ASCD.

2. American Psychiatric Association [APA] (2015, August 27). College students: Coping with stress and anxiety on campus.

3. Pascoe, M. C., Hetrick, S. E., \& Parker, A. G. (2020). The impact of stress on students in secondary school and higher education. International Journal of Adolescence and Youth, 25(1), 104-112, doi: 10.1080/02673843.2019.1596823

4. Cavanagh, S. R. (2019). The best (and Worst) ways to respond to student anxiety. The Chronicle in Higher Education. Retrieved from https://www.chronicle.com/article/The-Best-and-WorstWays-to/246226

5. Santini, F. O., Ladeira, W. J., Sampaio, C. H., \& Costa, G. S. (2017). Student satisfaction in higher education: A meta-analytic study. Journal of Marketing for Higher Education, 27(1), 1-18. doi: 10.1080/08841241.2017.1311980

6. Björkstrand, J., Schiller, D., Li, J., Davidson, P., Rosén J., Mårtensson, J. \& Kirk, U. (2019). The effect of mindfulness training on extinction retention. Scientific Reports, 9, 1-9.

7. Jacobs, G. D. (2001). The physiology of mind-body interactions: The stress response and the relaxation response. Journal of Alternative \& Complementary Medicine, 7(6), 83-92. https:// doi.org/10.1089/107555301753393841

8. Frith, E., Miller, S. \& Loprinzi, P. (2019). A Review of experimental research on embodied creativity: Revisiting the mind-body connection. Frontiers in Psychology, 10. 